\section{Traditional Psychological Tests Usage in Forensic Assessment}

\author{
Omnia E El-Shenawy* \\ Department of Psychology, Faculty of Arts, Menofia University, Shebeen \\ El-Koom, Egypt
}

mental health professionals such as psychologist or psychiatrist, this assessment is different from other assessments conducted for therapeutic purposes such as treatment planning and diagnosis, which will be discussed in the next section [2-5].

\section{Differences between Forensic Assessment and Therapeutic Assessment}

Heibrun and his colleagues determined differences between forensic assessment and therapeutic assessment in many aspects as following:

The first differences has to do with the purposes of each of them, while the primary purpose of forensic assessment as mentioned before is to provide the legal decision-maker by information about an individual's relevant capacities underlying the specific civil (e.g., child custody, personal injury) or criminal (e.g., competence to stand trial, sanity at the time of the offense) legal question. Therapeutic evaluation, by contrast, is usually conducted for diagnosis and treatment reasons $[5,6]$.

The second difference between the two types of assessments concerns with the nature of the examiner-examinee relationship. In forensic assessment, the psychologist or the psychiatrist plays an objective role or quasi- objective role in data collection and documentation, he or she concerns with objectivity and accuracy. While the role of the psychologist or the psychiatrist in therapeutic assessment is a helping role, he or she concerns with the person being evaluated [5].

The standards used in forensic and therapeutic assessment are different. Standards in therapeutic assessment help in diagnosis and treatment, and serve organizing, condensing, and orienting functions. While the forensic assessment include both clinical and legal standards. For example, when the evaluator is asked to consider the relation between the underlying mental, emotional, and cognitive deficits and a variety of legal issues, such as sentencing considerations, competencies, or criminal responsibility [5].

The fourth significant difference between the two types of assessment concerns with the sources of information used in each. Both of them rely on clinical data and psychosocial information through the utilization of self-report measures, psychological testing, and behavioral assessment. Unlike the therapeutic assessment, these sources are not sufficient for forensic assessment. More information is needed through the use of collateral information (e.g., document review, interviews) to assess the accuracy and consistency of gathered information by self-reports [6].

Individuals who are evaluated through forensic assessment have a lot of reasons to give inaccurate information. For example, some people may over-estimate their parent skills to obtain custody of their children, while others may exaggerate mental health problems in order to avoid criminal responsibility or to obtain monetary gain in personal injury cases, While

Received: September 14, 2017; Accepted: December 2, 2017; Published: December 18, 2017 
in most therapeutic evaluation cases, there is usually limited expectation about the possibility that the individual being evaluated will deliberately (through exaggeration or minimization) distort the nature of symptoms or experiences $[5,7]$.

Another difference between the therapeutic assessment and the forensic assessment has to do with the clarification of reasoning and the limits on knowledge. In therapeutic assessment, there is little expectation that the assumptions and methods used to complete the evaluation will be challenged, because therapeutic evaluation relies on the training, theoretical orientation, professional expertise, and knowledge of the evaluator. Unlike the therapeutic evaluation, forensic evaluation is conducted in an adversarial legal context, and is subject to challenge through rules of evidence or by cross-examination by opposing counsel [6].

Documentation and communication of results is another difference between therapeutic assessment and forensic assessment. In therapeutic evaluation, there is no identified expectation about the structure, format, level of detail, and content of the written report needed to document such evaluation. The reverse is true in forensic assessment, forensic evaluation reports tend to be lengthy and detailed due to the legal referral questions that require more information about the procedures, findings, and reasoning used in the assessment, and that has to do with the expectation that the assumptions and methods used in the evaluation will be challenged $[5,6]$.

Also there is an important distinction between the two type of assessment in light of verbal communication about the evaluation results. The likelihood that the therapeutic evaluator will give an expert witness in legal issues is rare. While the forensic evaluator should always testify as an expert witness and that testimony would be associated with the assessment, the forensic evaluator as an expert witness have to explain clearly to the trier of fact (often a jury, in some cases the judge) the theory that forms the context and framework for the tests used in the evaluation, how the tests were created, the ways in which the tests are used, how the results are interpreted, and the ways in which the test results at hand can be validly and reliably used, so that the attorney is unable to demonstrate that the expert is in fact not an expert in this area and has misunderstood, misused, or misstated the workings and results of the tests $[6,8]$.

The last difference between therapeutic assessment and forensic assessment is relevant to the previous point, the forensic assessment emphasis on psychometric considerations such as normative data, reliability, validity, and sensitivity. In contrast, therapeutic assessment relies on theoretical orientation of the practitioner and a corresponding array of assessment approaches and instruments [6], the following table summarize the differences between forensic assessment and therapeutic assessment:

\section{Standard Psychological Tests Used in Forensic Assessment}

A wide variety of assessment instruments and procedures are used in forensic assessments. These may include three major categories:
Forensic Assessment Instruments (FAIs), Forensically Relevant Instruments (FRIs), and Clinical Assessment Instruments (CAIs) [4,9].

\begin{tabular}{|c|c|c|}
\hline Purpose & Forensic assessment & Therapeutic assessment \\
\hline & $\begin{array}{l}\text { Helping legal decision- } \\
\text { maker }\end{array}$ & Diagnosis and treatment \\
\hline $\begin{array}{l}\text { Examiner-examinee } \\
\text { relationship }\end{array}$ & $\begin{array}{l}\text { Objective or quasi } \\
\text { objective role }\end{array}$ & Helping role \\
\hline Standards & $\begin{array}{l}\text { Clinical and legal } \\
\text { standards }\end{array}$ & Clinical standards \\
\hline Source of information & $\begin{array}{l}\text { Clinical, psychosocial, } \\
\text { and collateral information }\end{array}$ & $\begin{array}{c}\text { Clinical and psychosocial } \\
\text { information }\end{array}$ \\
\hline $\begin{array}{l}\text { Clarification of } \\
\text { reasoning and the limits } \\
\text { on knowledge }\end{array}$ & $\begin{array}{l}\text { Expectation to be } \\
\text { challenged }\end{array}$ & $\begin{array}{l}\text { No expectation to be } \\
\text { challenged }\end{array}$ \\
\hline $\begin{array}{l}\text { Documentation and } \\
\text { communication of } \\
\text { results }\end{array}$ & $\begin{array}{l}\text { Evaluation report tend to } \\
\text { be lengthy and detailed }\end{array}$ & $\begin{array}{c}\text { No identified expectation about } \\
\text { the structure, format, level } \\
\text { of detail, and content of the } \\
\text { evaluation report }\end{array}$ \\
\hline $\begin{array}{l}\text { Verbal communication } \\
\text { about the evaluation } \\
\text { results }\end{array}$ & $\begin{array}{l}\text { High expectation to } \\
\text { testify as an expert } \\
\text { witness }\end{array}$ & $\begin{array}{c}\text { No expectation to testify as an } \\
\text { expert witness }\end{array}$ \\
\hline Assessment base & $\begin{array}{c}\text { Psychometric } \\
\text { considerations (normative } \\
\text { data, reliability, validity, } \\
\text { and sensitivity) }\end{array}$ & $\begin{array}{l}\text { Theoretical orientation, } \\
\text { assessment approaches of the } \\
\text { practitioner }\end{array}$ \\
\hline
\end{tabular}

Table 1: Differences between forensic assessment and therapeutic assessment.

FAIs are specifically designed to directly assess psycho-legal constructs or capacities such as criminal defendant's competence to stand trial or an older person's ability to manage legal, financial and health care matters. Examples for FAIs are MacArthur competence assessment tool-criminal adjudication and the competence screening test $[4,10]$. While FAIs focus on psycho-legal constructs, FRIs focus on clinical constructs that are sometimes pertinent to legal context. Examples of FRIs include those used to assess malingering and "test taking set", recidivism, violence risk, and psychopathy [4]. The last category include CAIs which refer to standard psychological tests that primary designed to assess clinical constructs such as anxiety, depression, psychopathology and anger. These instruments are used in assessment, diagnosis, and treatment planning with clinical populations in therapeutic contexts $[4,9]$.

In addition, the field of Forensic assessment fall under two broad categories: civil and criminal. Civil areas of practice include the relationship between members of the community, and the goal is not to punish a wrongdoer but to prevent or compensate for a wrong. Examples of civil cases are custody evaluations and personal injury litigation. While the criminal practice typically include cases in which the criminal laws have been broken, and the goal is to appropriately punish the wrongdoer. Examples of Forensic assessment in criminal law would include competency to stand trial evaluations and sanity evaluations, in addition to capital sentencing mitigation [7,11].

Several survey studies have been conducted on psychological tests utilization in different forensic settings, and they have indicated consistently that psychological testing is an important component of most forensic evaluations, and the specific nature of the tests utilized varies by setting or evaluation focus [12]. And the most commonly used instruments in forensic assessment are the Minnesota Multiphasic Personality Inventory-2 (MMPI-2) for personality assessment and the Wechsler scales for intellectual measurement. 
In an early survey study conducted by Lees-Haley et al., to assess the frequency of various psychological tests used in forensic evaluations [13]. Data collected from reports of adult personal injury evaluations by 100 neuropsychological experts. The results indicated that the number of tests used in 100 forensic neuropsychological evaluations ranged from 1 to 32. And Wechsler Adult Intelligence Scale-Revised (WAIS-R) was the most often used scale, the MMPI /MMPI-2 was the second most frequently used, and the Wechsler Memory Scale (WMS)/Wechsler Memory Scale-Revised (WMS-R) ranked third.

Quinnell and Bow conducted a survey to explore the utilization of psychological tests in child custody evaluations by 198 psychologists [14]. Results indicated that half of the participants reported using IQ tests with children and adults as a part of custody evaluation. The MMPI /MMPI-2 was the second most frequently used objective tests with adults, and the Millon Clinical Multiaxial Inventory II or III (MCMI) was the second most used. Another tests were also used such as 16-Personality Factors and California Personality Inventory but on a limited basis. For adolescents testing, the Minnesota Multiphasic Personality Inventory- Adolescent Version (MMPI-A) was the commonly used with Millon Adolescent Clinical Inventory (MACI).

In an another survey conducted in Australia by Martin et al., to assess using of the psychological tests and how they are used among 79 Australian psychologists who working in private practice, government departments, or institutions that provide evaluations for the courts [15]. Results indicated that Wechsler Intelligence Scales and MMPI are rated as highly used tests. And the second most widely used personality tests were the PAI and the MCMI ranked as third.

In a recent survey conducted by Archer et al., to evaluate the psychological tests used in forensic assessments by members of the American Psychology-Law Society Division of the American Psychological Association, and by diplomates in the American Board of Forensic Psychology [12]. Participants were asked to report their test usage within specific categories, such as competency to stand trial, custody evaluations, and sex offender risk assessments. Further, survey results were also gathered for specific types of testing, such as cognitive/intellectual tests, multiscale inventories, neuropsychological tests, and single-scale tests. The results have demonstrated that the most traditional clinical assessment instruments used in forensic evaluations were the MMPI-2 and the wechsler intelligence scales. Results also indicated that other assessment measures, such as the Personality Assessment Inventory (PAI), and parent self-report measures (e.g., the Parenting Stress Index (PSI) are being used in the child evaluation arena along with more established instruments such as the Child Behavior Checklist (CBCL) and the Personality Inventory for Children (PIC).

Viljoen et al., surveyed forensic clinicians about the practices that they use in assessing violence risk in juvenile and adult offenders [16]. Participants were asked to rate their use of broad categories of tests (i.e., psychopathology tests, cognitive tests, risk assessment tools, and psychopathy tests). Also, clinicians were asked to list the specific tests that they used. Results indicated that for juvenile clinicians, the most commonly used tests included the wechsler intelligence scales, Minnesota multiphasic personality tests, and the Structured Assessment of Violence Risk in Youth. For adult clinicians, the most commonly used tests included the Hare psychopathy checklist tests, HCR-20, and the MMPI-II.

McLaughlin and Kan provided an update on the usage of assessment tools in evaluations of response style/malingering, Competency to Stand Trial (CST), mental state at time of alleged offense (MSO), and nonsexual violence risk by 102 forensic evaluators [17]. Results showed that test usage differed by type of assessment tool and type of forensic mental health assessment. FAIs/FRIs were the most frequently used in evaluations of response style/malingering, CST, and risk for nonsexual violence, and multiscale inventories such as MMPI-2, MMPI-2, MCMI and PAI were the most frequently used in MSO assessments. Evaluators used projective techniques (e.g., rorschach inkblot Test, Thematic Apperception Test) the least often across all four forensic issues.

In other survey study conducted by Neal and Grisso to explore forensic mental health professionals' self-reported utilization of structured tools in their forensic evaluations in civil and criminal contexts $(N$ $=434$ experts, 868 cases), Results showed that most of forensic mental health evaluations (74.2\%) used one or more structured tools to aid clinical judgment [18]. In addition personality assessment instruments were the most common kind of tool used which included the MMPI with any version, used in $15.2 \%$ of the evaluations and the PAI in $9.6 \%$ of the evaluations. These two tools were in the "top-ten" list for all of the 10 most common referral types. Results also indicated that several tools which were designed for specific kinds of referrals appeared most often or exclusively for those referrals. For example, the Historical Clinical Risk management 20 (HCR-20), a violence risk assessment tool was rated as number one tool for violence risk assessments (35.6\%). and Sexual Violence Risk-20(SVR-20), Risk for Sexual Violence Protocol (RSVP) and sex offender risk appraisal were used in sex offender risk assessments. Trial Competence Tools were used for CST evaluations, which included the Evaluation of Competence to Stand Trial-Revised (ECST-R), MacArthur Competence Assessment Tool-Criminal Adjudication (MacCAT-CA), and Juveniles' Adjudicative Competence Interview (JACI). The results also indicated that The Psychopathy Checklist-Revised (PCL-R) was another tool that most frequently used tool in violence risk assessments (35.6\%) and was also common in sex offender risk assessments, civil commitments, aid-in-sentence, and insanity evaluations. Response style or malingering tools were most common tools in insanity evaluations and 2 of the 10 for both CST and disability evaluations. For example, the Test of Memory Malingering (TOMM) was used in about $10 \%$ to $15 \%$ of insanity, disability and CST evaluations.

As seen in the survey research reviewed above, traditional psychological tests have a widespread use in different forensic contexts. However, it worth noting that there are both advantages and disadvantages of using traditional psychological tests in forensic evaluations. The first advantage is that most of them tend to be psychometrically structured and have an appropriate research base supporting its use in forensic assessment [19]. For example, there is an extensive body of research supported the forensic application of MMPI-2 [20-22]. In addition, most of these instruments can be particularly helpful for evaluating response style. The MMPI-2 for example, includes a number of scales that are useful in assessing various response styles, including defensiveness/denial (Scales K and S), display of positive attributes (Scale L), malingering, irrelevant responses, and exaggerated or faked responding $(\mathrm{F}, \mathrm{F}(\mathrm{B})$, and $\mathrm{F}(\mathrm{p}))[2,10]$. Also, clinical tests can provide a broad understanding of multiple areas of functioning [7]. Another value of using standardized psychological tests in forensic assessment is that the objectivity in evaluating persons, so their results are objective and provide valid information that are beyond that of impressionistic judgment [2]. 
Despite these advantages, psychological clinical instruments have many problems regarding its use in forensic settings. First, these instruments were developed for clinical purposes such as, diagnosis, and treatment planning not for forensic application [9]. Melton et al., indicated that most psychological tests have neither been developed nor validated for legal utilization [23]. The MMPI-2 for example, was developed for diagnostic purpose not for legal issues or standards; it has no scale to measure the competency to stand a trial [24].

Another problem regarding using psychological clinical tests for forensic purpose is the observation that the research base supporting this utilization varies according to the individual test. Meaning that, many of clinical tests used for forensic purpose have a supporting research base for its use in this context like the MMPI-2. While another tests have a little research base support or don't have any support [24].

In addition, standard psychological tests has less value in reconstructive evaluations (reconstruct an individual mental state at a prior point in time) than in assessments that focus on individual current mental state. The point is that some psychological functions are relatively stable over time (e.g., intelligence), while other aspects of personality and symptomatology such as anxiety and depression are less stable. The greater time length between time of assessment and time of interest, the greater likelihood that the test results can be influenced by natural or situational factors, therefore the forensic evaluator should use archival information [23].

Another problem with using psychological tests in forensic settings is that most of psychological tests are depended on self-reports. And self-report's results only reveal what people want to disclose about themselves. In addition, people are not always accurate about themselves. Self-report measures may result in inaccurate results in different forensic settings. In child custody evaluation, for example parents always overestimate their responses about positive attributes to get custody [25].

Despites these problems, research indicates that traditional psychological tests will continue to be used in forensic assessments. However many authors offered guidelines that assist forensic psychologists in selecting measures for particular utilization in forensic assessments that are worthy of consideration $[2,7,10,26]$.

\section{Considerations of Using Psychological Tests in Fo- rensic Assessments}

The first consideration of using traditional psychological tests in forensic assessments is that the given tests should have a desirable degree of standardization [7]. Standardization concerns with standardization group or normative sample, the basis on which the individual test score will be compared. Standardization group should be representative and large enough to make such comparison. The more dissimilar the person is from this standardization group, the less useful the test is for evaluation. Standardization also concerns with administration procedures, scoring, and interpretation of the results [27]. The wechsler intelligence scales and the various forms of the MMPI (MMPI-2, MMPI-2-RF, and MMPI-A) are examples of the standardized tests. As Archer et al., indicated The Wechsler Intelligence Scales for example, represent a highly adequate standardized test for utilization in forensic evaluations [7]. The test manuals for both the adult and child versions of the Wechsler Intelligence Scales clarify the conditions of test's administration, scoring, and results interpretations. In addition, the test does have applicability limits with the forensic population [7].
A second consideration of using psychological tests in forensic evaluation has to do with test reliability and validity. The forensic evaluator should consider the test reliability before using it in the evaluation process. The acceptable range of reliability depends partially on the variable being measured. In general, stable traits or abilities have higher reliabilities than changeable states. However, although a test can be reliable without being valid, the opposite is not true. The point is that the test must have achieved an adequate level of reliability [27]. The lower the reliability of a given test, the lower the limit on the validity of the construct being measured [26]. Thus, valid tests are those assess the constructs they are designed to assess. Nevertheless, high levels of test validity during its construction are not guaranteed its validity in specific situation because in practice, numerous variables might affect the test results. Validity in evaluation practice also depends on the extent to which tests can work together to improve each other's accuracy. Some tests have incremental validity (tests` ability to produce information above what is already known) in that they improve accuracy in additional information as increasing numbers of data sources are used [27].

The third consideration is that traditional psychological tests are of limit utility in directly answering psycho-legal questions. Therefore, forensic evaluator should use the psychological test that is relevant to the legal issue. As Heilbrun indicated that relevancy can be demonstrated either by directly measuring the legal constructs underlying a given forensic issue or by measuring a psychological construct that is assumed to be part of legal standard [26]. For example, intelligence scales could be used to assess the examinee ability to understand the charges against him. Related to this, Greenberg et al., recommended that forensic evaluators should consider the standard psychological tests they employ as generating conceptual hypotheses regarding the legal issues that can be accepted or rejected [10]. And that they should not be used without corroboration by other information concerns the matter.

In addition, the forensic evaluator should be aware of the scientific research base that clarifies the relation between the particular test results and relevant legal outcomes [23]. And, if there is no literature support the relation between the given test and legal issue, the forensic evaluator should clarify in his report the theoretical reasoning for test selection [26].

The other important consideration for psychological tests usage in forensic settings concerning with test results` interpretation. In gener$\mathrm{al}$, any psychological test results should be interpreted in light of standardization group that may limits its utilization in forensic evaluation [2]. As Groth-Marnat indicated a well-constructed test has specialized subgroup norms as well as basic standardization group norms [27]. Knowledge of each of these subgroup norms allows for a more appropriate and meaningful interpretation of scores. Unfortunately, that is not available for all psychological tests especially those used in forensic evaluation. Exception of this is the MMPI-2-RF, a broad measure of psychopathology that has basic norms for normal individuals, and a variety of comparison groups to support its utilization in populations of personal injury claimants, custody evaluation litigants and prison populations [7].

Heilbrun discussed another aspect of test results interpretation that has to do with individual's response style [26]. Response style refers to the nature and accuracy of the information provided by individuals being evaluated [6]. Virtually most individuals being evaluated in different contexts of forensic assessment may be motivated to make a 
special impression or be viewed in a particular way on the psychological evaluation therefore, Heilbrun recommended that psychological test results should be interpreted within the context of the individual's response style $[2,26]$. When response style appears to be malingering, defensive, or irrelevant, the results may need to be discounted or even ignored and other data sources should be used. As mentioned previously, the MMPI-2 has many scales that assess invalid response patterns than any other psychological measuring instruments [2].

\section{References}

1. Swerdlik C (2009) Psychological Testing and Assessment: An Introduction to Tests and Measurement (7thedn). McGraw-Hill's Primis Custom Publishing, New York, USA.

2. Butcher JN (2002) Assessment in Forensic Practice: An Objective Approach. In: Van Dorsten B (ed.). Forensic Psychology. Kluwer Academic Publishers, New York, Boston, London, Moscow. Pg no: 65-81.

3. O'donohue WT, Beitz K, Levensky ER (2003) An introduction to psychology for attorneys. In: O'donohue WT, Levensky ER (eds.). Handbook of Forensic Psychology: Resources for mental health and legal professionals. Elsevier Academic Press, New York, USA. Pg no: 27-44.

4. Heilbrun K, Marczyk GR, DeMatteo D, Zillmer EA, Harris J, et al. (2003) Principles of forensic mental health assessment: Implications for neuropsychological assessment in forensic contexts. Assessment 10: 329-343.

5. Otto RK, Heilbrun K (2002) The practice of forensic psychology. A look toward the future in light of the past. Am Psychol 57: 5-18.

6. Heibrun K, Marczyk G, Dematte D, Mack-Allen J (2007) A Principles-Based Approach to Forensic Mental Health Assessment. In: Goldstein AM (Ed.). Forensic psychology: Emerging topics and expanding roles (2ndedn). John Wiley \& Sons, Hoboken, New Jersey, USA. Pg no. 45-72.

7. Archer RP, Wheeler EM, Vauter RA (2016) Empirically Supported Forensic Assessment. Clinical Psychology: Science and Practice 23: 348-364.

8. Pope KS (1993) Multivariate Personality and Clinical Assessment in Court: Use of the Cattell Tests in Forensic Proceedings. Imagination, Cognition and Personality 13: 175-186.

9. Heilbrun K, Rogers R, Otto RK (2002) Forensic Assessment: Current Status and Future Directions. In: James RP. Ogloff (ed.). Taking psychology and law into the twenty-first century, Spinger Publishing, NewYork, USA. Pg no. 119-146.

10. Greenberg SA, Otto RK, Long AC (2003) The utility of psychological testing in assessing emotional damages personal injury litigation. Assessment 10: 411-419.

11. Mulien KL, Edens JF (2008) A case law survey of the Personality Assessment Inventory: Examining its role in civil and criminal trials. J Pers Assess 90: 300-303.

12. Archer RP, Buffington-Vollum JK, Stredny RV, Handel RW (2006) A survey of psychological test use patterns among forensic psychologists. J Pers Assess 87: 84-94.
13. Lees-Haley PR, Smith HW, Williams CW, Dunn JT (1996) Forensic neuropsychological test usage: An empirical survey. Archives of Clinical Neuropsychology 11: 45-51.

14. Quinnell FA, Bow JN (2001). Psychological tests used in child custody evaluations. Behav Sci Law 19: 491-501.

15. Martin M, Allan A, Allan M (2001) The Use of Psychological Tests by Australian Psychologists who do Assessments for the Courts. Australian Journal of Psychology 53: 77-82.

16. Viljoen JL, McLachlan K, Vincent GM (2010) Assessing violence risk and psychopathy in juvenile and adult offenders: A survey of clinical practices. Assessment 17: 377-395.

17. McLaughlin JL, Kan LY (2014) Test usage in four common types of forensic mental health assessment. Professional Psychology: Research and Practice 45: 128-135.

18. Neal T, Grisso T (2014) Assessment practices and expert judgment methods in forensic psychology and psychiatry: An international snapshot. Criminal Justice and Behavior 41: 1406-1421.

19. Craig RJ (2008) MMPI-Based Forensic Psychological Assessment of Lethal Violence. In: Hall HV (ed.). Forensic Psychology and Neuropsychology for Criminal and Civil Cases. Taylor \& Francis Group, London, UK. Pg no. 393-417.

20. Fox DD, Gerson A, Lees-Haley PR (1995) Interrelationship of MMPI-2 validity scales in personal injury claims. J Clin Psychol 51: 42-47.

21. Lees-Haley PR (1995). MMPI-2 base rates for 942 personal injury plaintiff $\mathrm{s}$ : Implications and challenges for forensic assessment. Journal of Clinical Psychology 53: 745-755.

22. Lees-Haley PR (1997) MMPI-2 base rates for 492 personal injury plaintiffs: Implications and challenges for forensic assessment. J Clin Psychol 53: 745-755.

23. Melton GB, Petrilla J, Poythress NG, Slobogin C (2007) Psychological evaluations for the courts: A handbook for mental health professionals and lawyers (3rdedn). Guilford Press, New York, USA.

24. Archer RP, Stredny RV, Wheeler EM (2013) forensic uses of clinical assessment instruments (2ndedn). Tayllor \& Francis Group, London, UK.

25. Sanders JD, Katz S (2013) The overuse and misuse of psychological testing: Why less is more. American Journal of Family Law 26: 221-226.

26. Heilbrun K (1992) The role of psychological testing in forensic assessment. Law and Human Behavior 16: 257-272.

27. Groth-Marnat G (2003) Handbook of psychological assessment (4thedn). John Wiley \& Sons, Hoboken, New Jersey, USA. 